\title{
Lateral epicondylalgia: midlife crisis of a tendon
}

\author{
James KH Luk *, Raymond CC Tsang, HB Leung
}

\section{A B S T R A C T}

The pathogenesis and management of lateral epicondylalgia, or tennis elbow, a common ailment affecting middle-aged subjects of both genders continue to provoke controversy. Currently it is thought to be due to local tendon pathology, pain system changes, and motor system impairment. Its diagnosis is usually clinical, based on a classical history, as well as symptoms and signs. In selected cases, additional imaging (X-rays, ultrasound, and magnetic resonance imaging) can help to confirm the diagnosis. Different treatment modalities have been described, including the use of orthotics, nonsteroidal anti-inflammatory drugs, steroid injections, topical glyceryl trinitrate, exercise therapy, manual therapy, ultrasound therapy, laser therapy, extracorporeal shockwave therapy, acupuncture, taping, platelet-rich plasma injections, hyaluronan gel injections, botulinum toxin injections, and

This article was published on $28 \mathrm{Feb}$ 2014 at www.hkmj.org. treatment is lacking and the choice of therapy depends on the experience of the management team, availability of the equipment and expertise, and patient response. This article provides a snapshot of current medical practice for lateral epicondylalgia management.

\begin{tabular}{l} 
Hong Kong Med J 2014;20:145-51 \\
\hline DOI: 10.12809/hkmj134110 \\
${ }^{1}$ JKH Luk *, FHKCP, FHKAM (Medicine) \\
${ }^{2}$ RCC Tsang, MScHC (PT), PDPT \\
${ }^{3}$ HB Leung, FHKCOS, FHKAM (Orthopaedic Surgery) \\
${ }^{1}$ Department of Medicine and Geriatrics, Fung Yiu King Hospital, 9 Sandy \\
Bay Road, Pokfulam, Hong Kong \\
${ }^{2}$ Physiotherapy Department, MacLehose Medical Rehabilitation Centre, 7 \\
Sha Wan Drive, Pokfulam, Hong Kong \\
${ }^{3}$ Department of Orthopaedics and Traumatology, Queen Mary Hospital, \\
102 Pokfulam Road, Pokfulam, Hong Kong \\
* Corresponding author: lukkh@ha.org.hk
\end{tabular}

\section{Introduction}

Tennis elbow is a diagnosis often heard in the community and usually associated with an uncomplicated clinical course. Surprisingly though, this minor self-limiting ailment is linked to much controversy with respect to nomenclature, pathophysiology, and management.

The term 'tennis elbow' was first used by Rungue in $1873 .{ }^{1}$ It also appeared in an 1883 paper by Major called 'Lawn-tennis elbow.' The name tennis elbow is itself a misnomer as it appears to be at least as common in non-tennis players. ${ }^{3}$ In the literature there are many names used to describe the condition, including lateral epicondylalgia (LE), lateral epicondylitis, lateral epicondylosis, shooter's elbow, archer's elbow, and simply lateral elbow pain. In the remainder of this article, the name 'lateral epicondylalgia' will be used. By definition, LE is a degenerative tendinopathy characterised by pain at the lateral epicondyle, aggravated by resisted muscle contraction of the extensor carpi radialis brevis (ECRB). ${ }^{4}$ Studies in western countries usually report an annual incidence of 4 to 7 per 1000 inhabitants, and at any given time it is said to affect 1 to $3 \%$ of individuals in the general population. ${ }^{5}$ Men and women seem to be equally predisposed to and the age of onset is usually between 35 and 55 years. A literature search yielded no epidemiological data pertaining to Hong Kong, China, or other Asian countries.

The typical duration of symptoms is between 6 and 24 months; up to $90 \%$ of sufferers report recovery within 1 year. However, 5 to $10 \%$ patients develop chronic symptoms and eventually undergo invasive treatment such as surgery.

The injury is usually attributed to eccentric contractions of the ECRB during backhand tennis swings, which leads to repetitive microtrauma resulting in tears at its origin. ${ }^{6}$ Others suggest that direct trauma to the lateral aspect of the elbow, hypovascularity, and fluoroquinolone antibiotics may also be involved. ${ }^{7,8}$

It is common to believe that tennis players are those most commonly affected by this condition. However, any behaviour or activity associated with overuse of underused and atrophied tendons can lead to LE. ${ }^{9}$ Indeed, many LE patients are not tennis players but subjects who have been sedentary for years, and then suddenly begin exercising (gardening, decorating a room, caring and lifting a baby, carrying heavy luggage).

\section{Pathophysiological model of lateral epicondylalgia}

Three interactive components seem to play a part in its pathophysiology, namely: local tendon pathology, pain system changes, and motor system impairment. ${ }^{10,11}$ The pathological changes in the 


\section{胘骨外上髁炎（網球肘）：肌腱的中年危機} 陸嘉熙、曾志聰、梁漢邦

胘骨外上髁炎（俗稱網球肘）是一種影響中年男女的常見疾病，其發 病機制及診治仍然備受爭議。目前認為胘骨外上髁炎的病因是由於局 部肌腱的病變、疼痛系統的變化和運動系統的損傷。臨床診斷通常是 基於典型的病史、症狀和體徵。對於一些病例來説, 額外的成像（X 射線、超聲波和核磁共振) 有助確診。此外, 文獻也有報導不同的治 療方法, 包括使用矯形器、非類固醇消炎止痛藥、類固醇注射、外用 硝酸甘油、運動療法、手法治療、超聲波治療、激光治療、體外衝擊 波療法、針炎、膠布治療、富血漿血小板注射、透明質酸凝膠注射 肉毒桿菌毒素注射, 以及手術治療。然而, 最佳的治療方法仍缺乏有 力的證據支持。至於選擇哪種治療方法須依賴管理團隊的經驗、是否 具專業人員和設備的協助, 以及病人反應。本文扼要探討目前胘骨外 上髁炎的臨床治療方法 tendon consist of angiofibroblastic hyperplasia with an increase in cell number and ground substance, vascular hyperplasia or neovascularisation, increased concentrations of neurochemicals, as well as disorganised and immature collagen formation. Ultrasonography (USG) has demonstrated different tendon pathology, including tendon thickening or thinning, focal areas of hypoechogenicity, tendon tears, calcification, and even bony irregularity. ${ }^{12}$ Doppler USG in LE patients has also demonstrated neovascularisation. The current view is that it is not an inflammation and hence the old term epicondylitis is a misnomer. ${ }^{13}$ Clinically, inflammation is only present during the very early stage of the disease and is very mild. On the contrary, there is a consistent absence of inflammatory cells, suggesting that the process is not an inflammatory process.

Change in pain perception (or the pain system) may also contribute to the pathophysiology of LE. It has been shown that substance $P$, a potent pain modulator, is located at the ECRB tendon. ${ }^{14}$ Moreover, LE is itself associated with hyperalgesia and increased response to noxious stimuli. Indeed, hyperalgesia can occur bilaterally and not be confined to the affected side. ${ }^{15}$ Furthermore, spread of reduced pain threshold beyond the LE site has been reported, especially over the cervical spine. Previous studies have actually reported a high prevalence of neck pain in patients with this condition. ${ }^{16}$

Motor system impairment consists of diminished strength, with morphological changes in muscle and altered motor control. ${ }^{17}$ It has been reported that both maximum hand grip and painfree grip are decreased, with the latter being considered more sensitive to assess LE and thence recommended as a clinical outcome measure. Patients with LE may have unilateral or bilateral handgrip weakness. Specific muscle strength deficits, including weakness in the wrist, hand, and shoulder have been demonstrated. At the histological level, moth-eaten fibres, fibre necrosis, signs of muscle fibre regeneration, and an increased proportion of fast muscle fibre types are found in the ECRB. ${ }^{18}$

Understanding the pathophysiology of LE may enable better targeting of treatment. The three model components mentioned above probably operate differently in different patients. Some patients with LE may have more pain system disturbance, while others may have more local tendon pathology. Clinicians should identify the relative involvement of local pathology, pain, and motor system dysfunction in each patient with LE. This may enable treatment strategies to be targeted better.

\section{Clinical presentation, physical examination, and investigation}

The classical description is pain at the lateral aspect of the elbow that often radiates down the forearm. The patient may recall a specific injury, but often the pain is gradual and of insidious onset. Weakness in grip or difficulty in carrying items in the hand is common and affects quality of life to a certain extent, depending on the severity of symptoms.

Physical examination should not be restricted to the affected elbow. Clinicians should begin with cervical spine, followed by entire upper limb, and careful examination of the shoulder. In the elbow, there will be tenderness at the lateral epicondyle, slightly distal to the extensor mass. The specific test includes the Thomson manoeuvre, in which pain is elicited by resisted wrist extension with the elbow in full extension and the forearm in pronation. ${ }^{19}$ Several other provocative tests aid in the diagnosis of LE, including the Chair test, the Bowden test, Cozen's test, and Mill's test. ${ }^{20}$ These tests cause pain over the lateral epicondyle by putting the ECRB in either eccentric contraction or passive tensioning. One should beware of radial nerve entrapment which affects $5 \%$ of LE patients, in which case pain may occur during resisted supination when the nerve is trapped within the supinator muscle. The middle finger extension test, resisted supination of the forearm, local anaesthetic radial tunnel block, the Rule-of-Nine test, and nerve conduction studies have all been described to help in the diagnosis of radial tunnel syndrome. ${ }^{21-24}$ However, diagnosis of radial nerve entrapment may be difficult when associated with LE. The elbow joint should also be checked for stability, range of movement, signs of arthritis, and joint effusion. Hand grip strength on the two sides has to be compared and the readings documented. The elbow is usually X-rayed to rule out other conditions. In about $25 \%$ of the patients, calcification is present in the soft tissues around the lateral epicondyle. ${ }^{25}$ If USG is available, it can detect tendon pathology, while Doppler USG may 
be able to demonstrate neovascularisation. Further investigations, such as magnetic resonance imaging, are usually unnecessary, unless there is serious concern about other articular pathology. ${ }^{26}$

\section{Treatment and outcome measurement}

To date, a standardised, universally accepted programme for LE treatment has not been established. Nor is there a consensus as to what outcomes to measure, which makes comparison of different treatment modalities difficult, if not impossible. Common outcomes evaluated in the literature include pain gauged by a visual analogue scale, hand grip strength, and pain-free grip strength. One validated outcome evaluation tool is the Patient-rated Forearm Evaluation Questionnaire, which has been translated into a Hong Kong Chinese version. ${ }^{27}$ This questionnaire has been updated by the originator and is called the Patient-rated Tennis Elbow Evaluation. ${ }^{28}$ Since no treatment protocol has been scientifically shown to be superior to others, more than 40 different therapeutic options have been offered to LE patients. To a large extent therefore, the choice depends on experience, expertise, and equipment at any given clinic or centre. Although treatment plans for LE vary in different centres, patient education is usually one of the important core elements.

\section{Evidence about different treatment options}

\section{Non-steroidal anti-inflammatory drugs}

Non-steroidal anti-inflammatory drugs (NSAIDs) can reduce pain but do not improve long-term outcome, and certainly they have their well-known side-effects, including gastro-intestinal bleeding and impairment of renal function. There is a theoretical risk of impaired tendon healing, as inflammation is important for granulation tissue, collagen growth, and tendon repair. Topical NSAIDs have been claimed to be beneficial for pain relief in some small studies lasting up to 4 weeks. ${ }^{29}$ As mentioned in a recent Cochrane review, evidence about the benefits of oral NSAIDs has been conflicting and no direct comparisons between oral and topical NSAIDs are available. ${ }^{30}$ Although there is evidence that NSAIDs are more effective than placebo for pain control, it is insufficient to support their routine use in LE.

\section{Corticosteroid injection}

Corticosteroid injection is an effective short-term means of achieving pain relief. However, their use for the treatment of LE has been increasingly discouraged, partly because no long-term benefit accrues, and partly due to high recurrence rates.
It is reported that $72 \%$ of patients treated with steroid injections experience a recurrence within 12 months, compared with $9 \%$ in those treated with a wait-and-see strategy. ${ }^{31}$ One recent study also demonstrated a recurrence rate as high as $34.7 \%$ in a steroid injection group. ${ }^{32}$ Another newly published randomised controlled trial shows that steroid injections result in lower rates of complete recovery compared to placebo and a greater 1-year recurrence rate. ${ }^{33}$ Theoretically, such injections can impair tendon healing, as inflammation is important for granulation tissue formation, collagen growth, and tendon repair. ${ }^{34}$ Hence, the use of corticosteroid injections for LE is a poor choice and should be avoided as far as possible even as initial treatment.

\section{Topical glyceryl trinitrate}

Interestingly, glyceryl trinitrate (GTN) can act as an agent to stimulate tendon healing. It is usually given as a GTN patch, stuck directly over the site of the LE (presumably for its psychological effect). Its side-effects include headache, dizziness, and skin irritation. In 2003, Paoloni et $\mathrm{al}^{35}$ reported a $21 \%$ greater effect in LE when GTN $(1.25 \mathrm{mg} / 24$ hours) was combined with exercise than with exercise alone. In 2009, the same investigators also reported a significant decrease in LE pain after 8 weeks of topical GTN (0.72 mg/24 hours). ${ }^{36}$ In 2011, McCallum et $\mathrm{al}^{37}$ followed up 58 patients treated for 6 months with topical GTN or placebo combined with a rehabilitation programme, but 5 years after discontinuation of therapy there was no difference in terms of pain and hand grip strength. These findings suggest that topical GTN did not offer additional long-term benefit.

\section{Exercise therapy}

Exercise is believed to stimulate tendon remodelling and produce muscular adaptive responses. Various resistance exercises have been prescribed to such patients, including isometric, isokinetic, and isotonic concentric or eccentric exercises. A recent systematic review ${ }^{38}$ including 10 studies of moderate quality and two studies of high quality supported the use of isotonic eccentric exercise for LE with moderate evidence of efficacy. It suggested that an eccentric exercise programme performed as three sets of 10 to 15 repetitions daily for about 6 to 12 weeks had the best supporting evidence as a means of reducing pain, improving function and pain-free grip strength, though optimal dosing was yet to be determined..$^{38}$ A recent meta-analysis showed that stretching plus strengthening exercises give better results than ultrasound plus friction massage alone. ${ }^{39}$

\section{Manual therapy}

Deep transverse friction massage (DTFM) relies 
on the theory of analgesia mediated via nonopioid descending pain inhibitory mechanisms. According to the Cochrane Library review, DTFM combined with other physiotherapy modalities was no better than physiotherapy alone for pain control, improvement of grip strength, and functionality. ${ }^{40}$

There are numerous manual therapy or manipulation techniques, variously named as Mills, Cyriax, Kaltenborn, Mennell, Stoddard Hartman, Maitland, and Mulligan. ${ }^{41}$ Their rationale, indications, and how they are applied vary. A more recent systematic review based on four randomised controlled trials of moderate-to-high quality found that Mulligan's manual mobilisation with movement provides better outcomes, such as pain-free hand grip strength over the short and long term when compared to placebo or other treatments such as ultrasound with exercise. ${ }^{42}$

\section{Taping}

The use of taping in LE is equally controversial and no firm conclusions can be drawn at this moment. Vicenzino et $\mathrm{al}^{43}$ compared diamond-shaped taping over placebo and found significant improvement in the intervention group in terms of the pressure pain threshold. However, other benefits were not demonstrated.

\section{Ultrasound therapy}

Recourse to ultrasound is commonly offered to LE patients, especially in the initial phase as it is readily available in most physiotherapy centres and is safe. Lundeberg et $\mathrm{al}^{44}$ reported that compared to placebo the pain of LE patients was better 3 months after such treatment, but there was no difference in global improvement. One study compared ultrasound to acupuncture and found that both yielded improvements in all outcome measures, but there was no difference between the groups. ${ }^{45}$ Due to the paucity of high-quality trials at this time, it is difficult to draw any conclusion to support or refute the use of ultrasound in LE.

\section{Extracorporeal shockwave therapy}

Derived from lithotripsy, extracorporeal shockwave therapy (ESWT) has been applied in orthopaedic treatment since 1987. The principle is to use shockwave technology to dissolve calcified deposits in diseased tendons. ${ }^{46}$ Lasting analgesia in the treated region has also been observed. Achilles quadriceps, triceps, and supraspinatus are common 'head upwards' tendinopathies treated with ESWT. However, it is known that calcification is rare in tendons that head downwards, such as those involved in LE. So why and how ESWT works in LE is unclear. The most accepted theory is that the microtrauma from repeated shockwaves to the affected area creates neovascularisation into the area and promotes tissue healing. ${ }^{47}$ Because re-inflammation is being induced, patients should not take anti-inflammatory medication, nor should they ice the area, but simple analgesics (such as paracetamol) may be acceptable. To date, the US Food and Drug Administration has only approved this treatment for plantar fasciitis and LE. ${ }^{48}$ Haake et $\mathrm{al}^{49}$ performed a placebo-controlled study entailing 3 weeks of ESWT versus placebo, but could not demonstrate any difference in outcomes, but more side-effects (reddening of skin and small haematomas) were reported with active treatment. In Hong Kong, a randomised controlled trial of 74 patients failed to demonstrate the beneficial effects of ESWT compared to placebo, ${ }^{50}$ as did another double-blind randomised controlled trial. ${ }^{51}$

\section{Laser therapy}

A recent systematic review and meta-analysis showed that laser therapy with an optimal dose of 904-nm wavelength applied to the extensor tendon insertions at the lateral elbow appears to provide short-term pain relief and reduce disability in LE, both alone and in combination with exercise therapy. ${ }^{52}$

\section{Orthotics}

Different commercially available 'tennis elbow' orthotics are being sold in stores. Most are in the form of tennis elbow braces made of neoprene material, and are not expensive. Whether they are useful is still not known. Jensen et $\mathrm{al}^{53}$ compared an off-the-shelf orthotic with steroid injections and concluded that both were similarly effective in early management. Wuori et $\mathrm{al}^{54}$ compared off-theshelf orthotics with placebo braces and could not demonstrate any difference. Garg et $\mathrm{al}^{55}$ reported that for patients with LE, a wrist extension splint can allow a greater degree of pain relief than a forearm strap brace. The message of the Cochrane Library is that due to the limited number of trials, few outcome measures, and limited long-term results, no definite conclusions on their effectiveness can be drawn..$^{56}$

\section{Acupuncture}

Acupuncture is a contemporary treatment modality for any type of painful condition, and LE is of no exception. ${ }^{57}$ Molsberger and Hille ${ }^{58}$ found that acupuncture could achieve pain relief for a longer period than placebo. Another study by Fink et al ${ }^{59}$ found that reduction in pain compared to placebo only occurred early after treatment but there was no difference after 2 months. Thus, there appears to be some evidence to support the efficacy of acupuncture over placebo, but the effect is not long-lasting. 


\section{Platelet-rich plasma injections}

The use of platelet-rich plasma (PRP) injections has created a plethora of hope for curing LE. The patient's own blood is drawn and centrifuged, and the buffy coat layer rich in platelet is isolated and injected into the patient. The PRP is rich in plateletderived growth factors which are chemoattractive for white blood cells and mesenchymal stem cells. It also contains transforming growth factor-beta, which promotes cell mitosis and increases type I collagen production in tendon sheath fibroblasts. It also has vascular endothelial growth factor that stimulates angiogenesis. These factors have been shown to be important in tendon repair. ${ }^{60}$ One randomised trial compared PRP injections with corticosteroid injections and reported superior cure rates and pain scores after PRP treatment. ${ }^{61}$ Currently, a large-scale study to evaluate the effectiveness of PRP is awaited, before definitive recommendations can be made for routine use. Regrettably, PRP treatment is not cheap and its cost-effectiveness is therefore an important consideration.

\section{Hyaluronan gel injection and botulinum toxin}

Hyaluronan gel injection is used in conditions such as osteoarthritis. A recent randomised controlled trial showed that for LE, it was superior to placebo injections. ${ }^{62}$ How it works is unclear but could be linked to effects on tendon degeneration; tendon being similar to cartilage, may derive benefit in LE akin to that in osteoarthritis. By contrast, injection of botulinum toxin into the extensor digitorum longus muscle of the third and fourth fingers to paralyse the muscle can unload the extensor tendon and help the patient recover from LE. ${ }^{63}$ Its disadvantage is that the patient cannot extend the third and fourth fingers for many months, which is disabling. It may be considered in patients with severe LE symptoms who do not want or are not suitable for surgery.

\section{Surgery}

It is estimated that about 4 to $11 \%$ patients ultimately undergo surgery. ${ }^{64}$ The usual indications include intractable symptoms, persistent symptoms despite conservative management (typically for at least 12 months). Many surgical procedures have been reported, including extensor release with intraarticular modifications, extensor fasciotomy, V-Y slide of the common extensor tendon, denervation of the lateral epicondyle, epicondylar resection with anconeus muscle transfer, and the Garden procedure with lengthening of the ECRB. ${ }^{65,66}$ Minimally invasive techniques are also available. It is beyond the scope of this review to describe each of these surgical procedures in detail. Regardless of the technique, successful treatment usually relies on patient selection, identification of pathology, and complete resection of the ECRB tendinosis. To date, evidence in support of surgery in LE is lacking, and the Cochrane Library has classified surgical treatment as having insufficient evidence to support or refute its use. ${ }^{67}$

\section{Conclusion}

Tennis elbow, or LE, is a common yet challenging condition to treat. Various non-surgical modalities have been described, the selection of which depends on experience of the management team, availability of the equipment, available expertise, and patient choice/response. In general, treatment can begin with patient education, application of commonly available treatments (physiotherapy, manual therapy, tennis elbow brace, as well as oral or topical NSAIDs). Steroid injection is not recommended as it lacks long-term benefit and is associated with a high relapse rate. When usual treatments fail to resolve symptoms, injection of PRP may be an option, but its efficacy and cost-effectiveness are not yet established. Injection of hyaluronate may also be tried before resorting to surgery. Surgery is usually indicated for resistant patients not responsive to non-surgical therapy. More research is needed to evaluate the best treatment modalities and protocols for LE sufferers.

\section{References}

1. Thurston AJ. Conservative and surgical treatment of tennis elbow: a study of outcome. Aust N Z J Surg 1998;68:568-72.

2. Major HP. Lawn-tennis elbow [letter]. BMJ 1883;2:557.

3. Shiri R, Viikari-Juntura E, Varonen H, Heliövaara M. Prevalence and determinants of lateral and medial epicondylitis: a population study. Am J Epidemiol 2006;164:1065-74.

4. Orchard J, Kountouris A. The management of tennis elbow. BMJ 2011;342:d2687.

5. Walker-Bone K, Palmer KT, Reading I, Coggon D, Cooper C. Prevalence and impact of musculoskeletal disorders of the upper limb in the general population. Arthritis Rheum 2004;51:642-51.

6. Riek S, Chapman AE, Milner T. A simulation of muscle force and internal kinematics of extensor carpi radialis brevis during backhand tennis stroke: implications for injury. Clin Biomech (Bristol, Avon) 1999;14:477-83.

7. Le Huec JC, Schaeverbeke T, Chauveaux D, Rivel J, Dehais J, Le Rebeller A. Epicondylitis after treatment with fluoroquinolone antibiotics. J Bone Joint Surg Br 1995;77:293-5.

8. Schneeberger AG, Masquelet AC. Arterial vascularization of the proximal extensor carpi radialis brevis tendon. Clin Orthop Relat Res 2002;(398):239-44.

9. Viikari-Juntura E, Kurppa K, Kuosma E, et al. Prevalence of epicondylitis and elbow pain in the meat-processing industry. Scand J Work Environ Health 1991;17:38-45.

10. Coombes BK, Bisset L, Vicenzino B. A new integrative model of lateral epicondylalgia. $\mathrm{Br} \mathrm{J}$ Sports Med 2009;43:252-8 
11. Fredberg U, Stengaard-Pedersen K. Chronic tendinopathy tissue pathology, pain mechanisms, and etiology with a special focus on inflammation. Scand J Med Sci Sports 2008;18:3-15.

12. Connell D, Burke F, Coombes P, et al. Sonographic examination of lateral epicondylitis. AJR Am J Roentgenol 2001;176:777-82.

13. Khan KM, Cook JL, Kannus P, Maffulli N, Bonar SF. Time to abandon the "tendinitis" myth. BMJ 2002;324:626-7.

14. Uchio Y, Ochi M, Ryoke K, Sakai Y, Ito Y, Kuwata S. Expression of neuropeptides and cytokines at the extensor carpi radialis brevis muscle origin. J Shoulder Elbow Surg 2002;11:570-5

15. Coombes BK, Bisset L, Vicenzino B. Thermal hyperalgesia distinguishes those with severe pain and disability in unilateral lateral epicondylalgia. Clin J Pain 2012;28:595601.

16. Berglund KM, Persson BH, Denison E. Prevalence of pain and dysfunction in the cervical and thoracic spine in persons with and without lateral elbow pain. Man Ther 2008;13:295-9.

17. Pienimäki T, Tarvainen T, Siira P, Malmivaara A, Vanharanta $\mathrm{H}$. Associations between pain, grip strength, and manual tests in the treatment evaluation of chronic tennis elbow. Clin J Pain 2002;18:164-70.

18. Ljung BO, Lieber RL, Fridén J. Wrist extensor muscle pathology in lateral epicondylitis. J Hand Surg $\mathrm{Br}$ 1999;24:177-83.

19. Van Hofwegen C, Baker CL 3rd, Baker CL Jr. Epicondylitis in the athlete's elbow. Clin Sports Med 2010;29:577-97.

20. Buckup K. Clinical tests for the musculoskeletal system: examinations-sign-phenomena. 2nd ed. Stuttgart: NY Thieme; 2008: 129-33.

21. Roles NC, Maudsley RH. Radial tunnel syndrome: resistant tennis elbow as a nerve entrapment. J Bone Joint Surg Br 1972;54:499-508.

22. Lister GD, Belsoe RB, Kleinert HE. The radial tunnel syndrome. J Hand Surg Am 1979;4:52-9.

23. Ritts GD, Wood MB, Linscheid RL. Radial tunnel syndrome. A ten-year surgical experience. Clin Orthop Relat Res 1987;219:201-5.

24. Loh YC, Lam WL, Stanley JK, Soames RW. A new clinica test for radial tunnel syndrome-the Rule-of-Nine test: a cadaveric study. J Orthop Surg (Hong Kong) 2004;12:83-6.

25. Edelson G, Kunos CA, Vigder F, Obed E. Bony changes at the lateral epicondyle of possible significance in tennis elbow syndrome. J Shoulder Elbow Surg 2001;10:158-63.

26. Tuite MJ, Kijowski R. Sports-related injuries of the elbow: an approach to MRI interpretation. Clin Sports Med 2006;25:387-408, v.

27. Leung HB, Yen CH, Tse PY. Reliability of Hong Kong Chinese version of the Patient-rated Forearm Evaluation Questionnaire for lateral epicondylitis. Hong Kong Med J 2004;10:172-7.

28. Macdermid J. Update: The Patient-rated Forearm Evaluation Questionnaire is now the Patient-rated Tennis Elbow Evaluation. J Hand Ther 2005;18:407-10.

29. Burnham R, Gregg R, Healy P, Steadward R. The effectiveness of topical diclofenac for lateral epicondylitis. Clin J Sport Med 1998;8:78-81.

30. Pattanittum P, Turner T, Green S, Buchbinder R. Nonsteroidal anti-inflammatory drugs (NSAIDs) for treating lateral elbow pain in adults. Cochrane Database Syst Rev 2013;(5):CD003686.
31. Bisset L, Beller E, Jull G, Brooks P, Darnell R, Vicenzino B. Mobilisation with movement and exercise, corticosteroid injection, or wait and see for tennis elbow: randomised trial. BMJ 2006;333:939.

32. Mardani-Kivi M, Karimi-Mobarakeh M, Karimi A, et al. The effects of corticosteroid injection versus local anesthetic injection in the treatment of lateral epicondylitis: a randomized single-blinded clinical trial. Arch Orthop Trauma Surg 2013;133:757-63.

33. Coombes BK, Bisset L, Brooks P, Khan A, Vicenzino B. Effect of corticosteroid injection, physiotherapy, or both on clinical outcomes in patients with unilateral lateral epicondylalgia: a randomized controlled trial. JAMA 2013;309:461-9.

34. Behrens SB, Deren ME, Matson AP, Bruce B, Green A. A review of modern management of lateral epicondylitis. Phys Sportsmed 2012;40:34-40.

35. Paoloni JA, Appleyard RC, Nelson J, Murrell GA. Topical nitric oxide application in the treatment of chronic extensor tendinosis at the elbow: a randomized, doubleblinded, placebo-controlled clinical trial. Am J Sports Med 2003;31:915-20.

36. Paoloni JA, Murrell GA, Burch RM, Ang RY. Randomised, double-blind, placebo-controlled clinical trial of a new topical glyceryl trinitrate patch for chronic lateral epicondylosis. Br J Sports Med 2009;43:299-302.

37. McCallum SD, Paoloni JA, Murrell GA. Five-year prospective comparison study of topical glyceryl trinitrate treatment of chronic lateral epicondylosis at the elbow. Br J Sports Med 2011;45:416-20.

38. Raman J, MacDermid JC, Grewal R. Effectiveness of different methods of resistance exercises in lateral epicondylosis - a systematic review. J Hand Ther 2012;25:526.

39. Hoogvliet P, Randsdorp MS, Dingemanse R, Koes BW, Huisstede BM. Does effectiveness of exercise therapy and mobilisation techniques offer guidance for the treatment of lateral and medial epicondylitis? A systematic review. Br J Sports Med 2013;47:1112-9.

40. Brosseau L, Casimiro L, Milne S, et al. Deep transverse friction massage for treating tendinitis. Cochrane Database Syst Rev 2002;(4):CD003528

41. Vicenzino B. Lateral epicondylalgia: a musculoskeletal physiotherapy perspective. Man Ther 2003;8:66-79.

42. Herd CR, Meserve BB. A systematic review of the effectiveness of manipulative therapy in treating lateral epicondylalgia. J Man Manip Ther 2008;16:225-37.

43. Vicenzino B, Brooksbank J, Minto J, Offord S, Paungmali A. Initial effects of elbow taping on pain-free grip strength and pressure pain threshold. J Orthop Sports Phys Ther 2003;33:400-7.

44. Lundeberg T, Abrahamsson P, Haker E. A comparative study of continuous ultrasound, placebo ultrasound and rest in epicondylalgia. Scand J Rehabil Med 1988;20:99101.

45. Davidson J, Vandervoort A, Lessard L, et al. The effect of acupuncture versus ultrasound on pain level, grip strength and disability in individuals with lateral epicondylitis: a pilot study. Physiother Can 2001;53:195-202.

46. Furia JP. High-energy extracorporeal shock wave therapy as a treatment for insertional Achilles tendinopathy. Am J Sports Med 2006;34:733-40.

47. Ko JY, Chen HS, Chen LM. Treatment of lateral epicondylitis of the elbow with shock waves. Clin Orthop 
Relat Res 2001;(387):60-7.

48. Wang CJ. Extracorporeal shockwave therapy in musculoskeletal disorders. J Orthop Surg Res 2012;7:11.

49. Haake M, König IR, Decker T, et al. Extracorporeal shock wave therapy in the treatment of lateral epicondylitis: a randomized multicenter trial. J Bone Joint Surg Am 2002;84-A:1982-91.

50. Leung HB, Yen $\mathrm{CH}$, Yip C, Tse PY. A prospective randomized double-blinded controlled study on extracorporeal shockwave therapy for lateral epicondylitis. Hong Kong J Orthop Surg 2002;6(Suppl):S12.

51. Staples MP, Forbes A, Ptasznik R, Gordon J, Buchbinder R. A randomized controlled trial of extracorporeal shock wave therapy for lateral epicondylitis (tennis elbow). J Rheumatol 2008;35:2038-46.

52. Bjordal JM, Lopes-Martins RA, Joensen J, et al. A systematic review with procedural assessments and meta-analysis of low level laser therapy in lateral elbow tendinopathy (tennis elbow). BMC Musculoskelet Disord 2008;9:75.

53. Jensen B, Bliddal H, Danneskiold-Samsøe B. Comparison of two different treatments of lateral humeral epicondylitis"tennis elbow". A randomized controlled trial [in Danish]. Ugeskr Laeger 2001;163:1427-31.

54. Wuori JL, Overend TJ, Kramer JF, MacDermid J. Strength and pain measures associated with lateral epicondylitis bracing. Arch Phys Med Rehabil 1998;79:832-7.

55. Garg R, Adamson GJ, Dawson PA, Shankwiler JA, Pink MM. A prospective randomized study comparing a forearm strap brace versus a wrist splint for the treatment of lateral epicondylitis. J Shoulder Elbow Surg 2010;19:50812.

56. Struijs PA, Smidt N, Arola H, van Dijk CN, Buchbinder R, Assendelft WJ. Orthotic devices for the treatment of tennis elbow. Cochrane Database Syst Rev 2002;(1):CD001821.
57. Trinh KV, Phillips SD, Ho E, Damsma K. Acupuncture for the alleviation of lateral epicondyle pain: a systematic review. Rheumatology (Oxford) 2004;43:1085-90.

58. Molsberger A, Hille E. The analgesic effect of acupuncture in chronic tennis elbow pain. Br J Rheumatol 1994;33:11625.

59. Fink M, Wolkenstein E, Karst M, Gehrke A. Acupuncture in chronic epicondylitis: a randomized controlled trial. Rheumatology (Oxford) 2002;41:205-9.

60. Molloy T, Wang Y, Murrell G. The roles of growth factors in tendon and ligament healing. Sports Med 2003;33:381-94.

61. Mishra AK, Skrepnik NV, Edwards SG, et al. Efficacy of platelet-rich plasma for chronic tennis elbow: a doubleblind, prospective, multicenter, randomized controlled trial of 230 patients. Am J Sports Med 2014;42:463-71.

62. Petrella RJ, Cogliano A, Decaria J, Mohamed N, Lee R. Management of tennis elbow with sodium hyaluronate periarticular injections. Sports Med Arthrosc Rehabil Ther Technol 2010;2:4.

63. Wong SM, Hui AC, Tong PY, Poon DW, Yu E, Wong LK. Treatment of lateral epicondylitis with botulinum toxin: a randomized, double-blind, placebo-controlled trial. Ann Intern Med 2005;143:793-7.

64. Nirschl RP, Pettrone FA. Tennis elbow. The surgical treatment of lateral epicondylitis. J Bone Joint Surg Am 1979;61:832-9.

65. Rose NE, Forman SK, Dellon AL. Denervation of the lateral humeral epicondyle for treatment of chronic lateral epicondylitis. J Hand Surg Am 2013;38:344-9.

66. Tosti R, Jennings J, Sewards JM. Lateral epicondylitis of the elbow. Am J Med 2013;126:357.e1-6.

67. Buchbinder R, Johnston RV, Barnsley L, Assendelft WJ, Bell SN, Smidt N. Surgery for lateral elbow pain. Cochrane Database Syst Rev 2011;(3):CD003525. 